Koichi Kugimiya*, Takahiro Kozawa, Takashi Harada and Makio Naito

\title{
Mechano-chemical synthesis of ammonia and acetic acid from inorganic materials in water
}

https://doi.org/10.1515/gps-2018-0073

Received April 6, 2018; accepted July 20, 2018; previously published online September 12, 2018

\begin{abstract}
A mechano-chemical reaction formed by a simple high-energy ball milling was applied to simulate the synthesis of ammonia and organic precursors from common inorganic materials that occurred on early Earth. By milling for $0.5-64 \mathrm{~h}$ at centrifugal accelerations of 20-150 G, ammonia and acetic acid were produced from inorganic materials, such as iron nitride, nitrate, carbide, and carbonates, in water. The experimental results can offer waste processing of metallic acids by the mechanical method without using any alkaline sources and suggest that the high-energy milling technology provides a new synthesis mode to form wide ranges of organic materials and scope for broader applications. This study also offers a new route to the formation of the precursors on early Earth and proposes that tremors and friction initiate micro-impacts between rocks and sand in the terrestrial crust, resulting in the formation of ammonia and organic materials from inorganic materials.
\end{abstract}

Keywords: ammonia; ball mill; impact; mechanochemical reaction; meteorite.

\section{Introduction}

Ammonia is indispensable for use in numerous chemicals such as fertilizers and is industrially produced from nitrogen and hydrogen by the Haber-Bosch process. Ammonia is assumed to have been one of the essential amino acid precursors and thus an important contributor to the origin of life on early Earth 4.6 billion years ago. To reproduce

\footnotetext{
*Corresponding author: Koichi Kugimiya, Joining and Welding Research Institute, Osaka University, 11-1 Mihogaoka, Ibaraki, Osaka 567-0047, Japan, e-mail: kugimiya.1q3@hotmail.co.jp, mechem_kk@jwri.osaka-u.ac.jp

Takahiro Kozawa and Makio Naito: Joining and Welding Research Institute, Osaka University, 11-1 Mihogaoka, Ibaraki, Osaka 5670047, Japan
}

Takashi Harada: Research Center for Solar Energy Chemistry, Osaka University, 1-3 Machikaneyama, Toyonaka, Osaka 560-8531, Japan

Ә Open Access. (c) BY @ 2019 Walter de Gruyter GmbH, Berlin/Boston the synthesis of ammonia on early Earth, a shock wave method using a single-stage propellant gun has been reported [1], which reproduces a meteorite plume consisting of nitrogen, water, and iron as one of the extraterrestrial materials vaporized by meteorite impacts $[2,3]$. The shock wave parameters delivered to the specimens by the single-stage propellant gun were estimated to be about $6 \mathrm{GPa}$ and $2900 \mathrm{~K}$, with a much higher shock pressure of about $20 \mathrm{GPa}$ applied to the container [1, 4]. A rate of up to $8 \%$ was obtained for the conversion of nitrogen to ammonia. Under similar conditions for forming organic precursors, shock pressure of $6 \mathrm{GPa}$, temperature of $5000 \mathrm{~K}$, and duration of $0.7 \mu$ sere reported [5]. These shock wave conditions were much more severe compared to the mild conditions of the Haber-Bosch process ( $700 \mathrm{~K}$ and $\sim 30 \mathrm{MPa}$ ) containing catalysts such as iron and were unsuitable for the production of a wide range of organic materials.

As ceramists well know, mild conditions for forming ammonia and organic materials can also be obtained using the simple and traditional method of ball milling. As illustrated in Figure 1, collisions between small milling balls $(\phi 2-5 \mathrm{~mm})$ simulate meteorites colliding with Earth, with the micro-impacts from the balls delivering a high temperature $(>1000 \mathrm{~K})$ and pressure $[6,7]$. In particular, high-energy milling methods such as the nanopowder process are assumed to be most suitable not only for producing local high-temperature and high-pressure conditions but also for delivering higher ball impact frequencies, yielding higher reaction rates [8]. Mechano-chemical (MeChem) reactions, which utilize a characteristic field of micro-impacts, are widely used in the synthesis of ceramic powders [9]. Additionally, MeChem reactions have been used in the decomposition of organic materials, in hydrogen production [10], and in the formation of metal nitrides in ammonia gas [11].

Herein we report the reverse reaction under extremely high MeChem impact fields: the formation of ammonia from nitrides and nitrates and the formation of simple organic precursors from inorganic materials such as iron carbide and metal carbonates. A new route to the organic precursors of amino acids is proposed regarding the origin of life on early Earth, and extended to the formation of precursors in the deep terrestrial crusts caused by diastrophisms such as seismic tremors. 
A

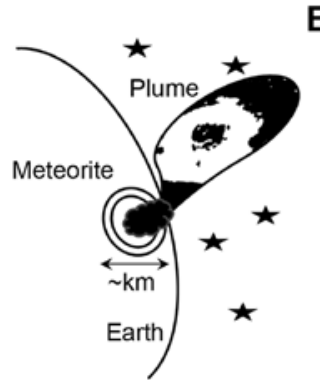

B

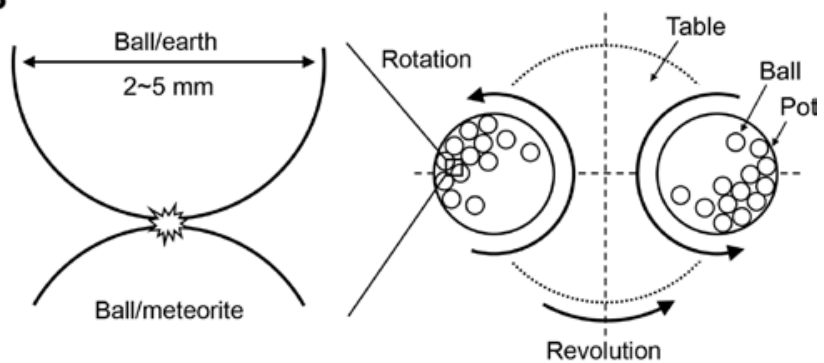

Figure 1: Schematic illustrations of (A) a meteorite impact and (B) a high-energy ball mill showing micro-impact fields.

\section{Materials and methods}

Planetary ball mills (High-G BX254E and X382, Kurimoto, Osaka, Japan), a type of high-energy milling machine, were used as they can accommodate two pots at a time and create a continuous centrifugal acceleration of up to $150 \mathrm{G}$. $\mathrm{Fe}_{4} \mathrm{~N}$ (99.9\% purity, Kojundo Chemical Laboratory, Saitama, Japan), $\mathrm{Fe}_{3} \mathrm{C}(99.9 \%$, Rare Metallic, Tokyo, Japan), $\mathrm{Fe}\left(\mathrm{NO}_{3}\right)_{3} \cdot 9 \mathrm{H}_{2} \mathrm{O}(98.5 \%), \mathrm{CaCO}_{3}(99.5 \%), \mathrm{MnCO}_{3}(99.9 \%), \mathrm{FeS}$ $(>70 \%)$ (Kanto Chemical, Tokyo, Japan), and montmorillonite (naturally occurring mineral, Alfa Aesar, Lancashire, UK) were used as the starting materials. The purity of these chemicals was reported by each manufacturer. The clay montmorillonite was added to reduce excessive impact forces and concentrate the reactants by adsorption. The experimental conditions are summarized in Table 1. It is noted that all the reagents were inorganic materials and the total amount used in each experiment was much greater than that used in the gunshot experiment $[1,5]$. A stainless steel (SUS) vessel was used as the milling pot. Zirconia balls of different diameters $(\phi 2-5 \mathrm{~mm})$ were used, except for specimens $2 \mathrm{a}$ and $2 \mathrm{~b}$, for which SUS balls were used. The milling operations were carried out in the range 20-150 G for $0.5-64 \mathrm{~h}$. The centrifugal acceleration was calculated using technical data such as revolution diameter and frequency of the motor $(F)$. The detailed calculation process has been described by Hashishin et al. [12], wherein they used the same planetary ball mill as that used in this study. Basically, the centrifugal acceleration $\left(g^{\star}\right)$ was controlled from the equation $g^{\star}=0.0441 \cdot F^{2}$. After milling, the resulting muddy products were collected and separated into solids and liquids by centrifugation or filtration.

The crystalline phases of the products were identified by powder X-ray diffraction (XRD; Bruker AXS, D2 PHASER, Karlsruhe, Germany) using $\mathrm{Cu} \mathrm{K} \alpha$ radiation. The total $\mathrm{C} / \mathrm{N}$ contents in the solutions were evaluated using a total organic carbon (TOC) analyzer (Shimadzu, TOC-L CPH, Kyoto, Japan). Some specimens were examined at analytical institutes (ITES, Shiga, Japan, and Hitachi High-Tech Science Corporation, Tokyo, Japan) by standard procedures using a gas chromatograph mass spectrometer (GCMS; Perkin Elmer XL/ TurboMass, column: DB-5 at a temperature of $50-320^{\circ} \mathrm{C}$, MS scan: 35-600, MS sim: 45, 57, 60, 73, 74, 88, and 102), an ion chromatography (IC) system (Thermo Fisher Scientific/ICS-1100, column: CS12A at $35^{\circ} \mathrm{C}$, intake: $25 \mu \mathrm{l}$ ), and an amino acid analyzer (Hitachi LA8080 AminoSAAYA, column: $2622 \mathrm{PH}$ at $135^{\circ} \mathrm{C}$, intake: $20 \mu \mathrm{l}$ ).

\section{Results and discussion}

Upon opening the pots after milling, a strong ammonia or sewage-like odor was detected, confirming the formation of ammonia. Furthermore, an increase in $\mathrm{pH}$ for all conditions, as shown in Table 2, suggested the formation of a strong alkaline material. Ammonia was identified as the only possible compound that could have formed from the starting materials, based on the experimental conditions (nitrogen - from the air, $\mathrm{ZrO}_{2}$ balls, and water). These results indicate that waste processing of metal acids can be done by MeChem reactions without using any alkaline sources.

For specimen 1, the resulting black muddy paste bubbled for some time and produced a strong ammonia smell. This paste had a high $\mathrm{pH}$ of 11 as shown in Table 2.

Table 1: Experimental conditions and starting materials.

\begin{tabular}{|c|c|c|c|c|c|c|c|}
\hline \multirow[t]{2}{*}{ No. } & \multirow[t]{2}{*}{ Milling machine and conditions } & \multicolumn{6}{|c|}{ Starting materials (g) } \\
\hline & & $\mathrm{Fe}_{4} \mathrm{~N}$ & Fe nitrate & Clay & C sources & $\mathrm{H}_{2} \mathrm{O}$ & Others \\
\hline 1 & $\mathrm{BX}, 150 \mathrm{G}, 64 \mathrm{~h}, 5 \phi\left(\mathrm{ZrO}_{2}\right)$ & 4.01 & & 1.05 & & 50 & \\
\hline $2 a$ & $\mathrm{X}, 20 \mathrm{G}, 0.5 \mathrm{~h}, 4 \phi$ (SUS) & & 7.00 & & & 170 & \\
\hline $2 b$ & X, 20 G, 1 h, $4 \phi$ (SUS) & & 7.00 & & & 170 & \\
\hline $3 a$ & $\mathrm{X}, 40 \mathrm{G}, 39 \mathrm{~h}, 2 \phi\left(\mathrm{ZrO}_{2}\right)$ & 12.03 & & 3.00 & $\mathrm{Fe}_{3} \mathrm{C} 18.21$ & 150 & \\
\hline $3 b$ & $\mathrm{X}, 40 \mathrm{G}, 39 \mathrm{~h}, 2 \phi\left(\mathrm{ZrO}_{2}\right)$ & & 6.80 & 3.00 & $\mathrm{MnCO}_{3} 11.60$ & 150 & \\
\hline 4 & $\mathrm{BX}, 50 \mathrm{G}, 16 \mathrm{~h}, 2 \phi\left(\mathrm{ZrO}_{2}\right)$ & & 3.52 & & $\mathrm{CaCO}_{3} 8.76$ & 50 & FeS 7.69 \\
\hline 5 & $\mathrm{BX}, 40 \mathrm{G}, 30 \mathrm{~h}, 2 \phi\left(\mathrm{ZrO}_{2}\right)$ & 2.03 & 1.16 & 0.50 & $\mathrm{Fe}_{3} \mathrm{C} 6.14$ & 60 & \\
\hline
\end{tabular}


Table 2: Summary of experimental results.

\begin{tabular}{|c|c|c|c|c|c|}
\hline No. & Starting materials & Main phases from XRD & Smella & $\mathrm{pH}$ change & Inner pressure \\
\hline 1 & $\mathrm{Fe}_{4} \mathrm{~N}$, clay & $\mathrm{Fe}_{3} \mathrm{O}_{4}$ & SN & $7 \rightarrow 11$ & High \\
\hline $2 a$ & Fe nitrate & $\mathrm{Fe}_{3} \mathrm{O}_{4}$ & so & $2 \rightarrow 8$ & Low \\
\hline $2 b$ & Fe nitrate & $\mathrm{Fe}_{3} \mathrm{O}_{4}$ & SN & $2 \rightarrow 9$ & Low \\
\hline $3 a$ & $\mathrm{Fe}_{4} \mathrm{~N}, \mathrm{Fe}_{3} \mathrm{C}$, clay & $\mathrm{Fe}_{3} \mathrm{O}_{4}$ & so & $7 \rightarrow 11$ & High \\
\hline $3 b$ & Fe nitrate, $\mathrm{MnCO}_{3}$, clay & $\mathrm{MnCO}_{3}, \mathrm{Fe}_{3} \mathrm{O}_{4}$ & so & $2 \rightarrow 10$ & Low \\
\hline 4 & Fe nitrate, $\mathrm{CaCO}_{3}, \mathrm{FeS}$ & $\mathrm{CaCO}_{3}, \mathrm{Fe}_{3} \mathrm{O}_{4}$ & so & $2 \rightarrow 9$ & Low \\
\hline 5 & Fe nitrate, $\mathrm{Fe}_{4} \mathrm{~N}, \mathrm{Fe}_{3} \mathrm{C}$, clay & $\mathrm{Fe}_{3} \mathrm{O}_{4}$ & so & $2 \rightarrow 11$ & Low \\
\hline
\end{tabular}

${ }^{a} \mathrm{SN}$, Strong ammonia smell; SO, sewage-like odor.

The XRD pattern of the dried product for specimen 1 indicated that $\mathrm{Fe}_{4} \mathrm{~N}$ was completely decomposed into $\mathrm{Fe}_{3} \mathrm{O}_{4}$ (Figure 2). Elemental analysis of the mud by energy-dispersive X-ray spectrometry detected the presence of $\mathrm{Zr}$, Cr, and $\mathrm{Ni}$, besides $\mathrm{Fe}$, which revealed some erosion of the SUS pot and $\mathrm{ZrO}_{2}$ balls. The SUS pot was eroded by about $1.8 \mathrm{~g}$, which was non-negligible compared to the amount of starting materials. A shorter milling time and reduced centrifugal acceleration are expected to effectively reduce erosion.

Unlike the gunshot impacts, the micro-impact fields generated by small balls (Figure 1) are not so intense as to disintegrate molecules into atomic elements, but still sufficient to activate the particle surfaces. An intermediate such as HO-Fe-NH is formed on the surface of $\mathrm{Fe}_{4} \mathrm{~N}$ particles which reacts with $\mathrm{H}_{2} \mathrm{O}$ molecules and decomposes into $\mathrm{Fe}_{3} \mathrm{O}_{4}$ and $\mathrm{NH}_{3}$. Based on the resulting $\mathrm{pH}$ of 11 and water content of $50 \mathrm{~g}$, the conversion rate from $\mathrm{Fe}_{4} \mathrm{~N}$ to ammonia was calculated to be about $30 \%$. Most of the remaining nitrogen was likely released from the pot as a gas. This conversion rate is much higher than that observed in the gun shock wave experiment (8\%) [1]. The reactions may

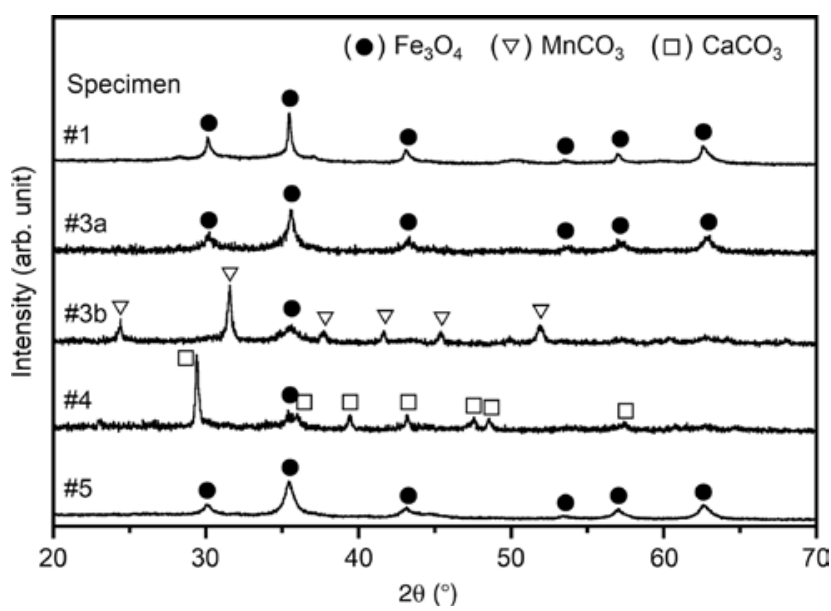

Figure 2: XRD patterns of the products after high-energy ball milling. take place similar to a hydrothermal decomposition and are given by the following equations:

$$
\begin{aligned}
& \mathrm{Fe}_{4} \mathrm{~N}+16 / 3 \mathrm{H}_{2} \mathrm{O} \rightarrow 4 / 3 \mathrm{Fe}_{3} \mathrm{O}_{4}+\mathrm{NH}_{3}+23 / 6 \mathrm{H}_{2} \\
& \mathrm{Fe}_{4} \mathrm{~N}+16 / 3 \mathrm{H}_{2} \mathrm{O} \rightarrow 4 / 3 \mathrm{Fe}_{3} \mathrm{O}_{4}+1 / 2 \mathrm{~N}_{2}+16 / 3 \mathrm{H}_{2}
\end{aligned}
$$

The side reaction of the eroded metal also produces hydrogen:

$$
3 \mathrm{Fe}+4 \mathrm{H}_{2} \mathrm{O} \rightarrow \mathrm{Fe}_{3} \mathrm{O}_{4}+4 \mathrm{H}_{2}
$$

The excessive formation of nitrogen and hydrogen can produce a high pressure inside the pot. The observed bubbles were thus due to the release of $\mathrm{H}_{2}$ and $\mathrm{NH}_{3}$ from the clay.

The formation of $\mathrm{Fe}_{3} \mathrm{O}_{4}$ instead of the $\mathrm{FeO}$ phase is expected even under high hydrogen pressure if adequate moisture is present. When the ratio of the partial pressure of $\mathrm{H}_{2} \mathrm{O}$ to that of $\mathrm{H}_{2}$ is about 10 or above at the presumed temperature of $1000 \mathrm{~K}$, the $\mathrm{Fe}_{3} \mathrm{O}_{4}$ phase is stable $[13,14]$. When the partial pressure ratio is less than 1 or hydrogen pressure is much higher, $\mathrm{FeO}$ becomes more stable. This oxide transformation corresponds well to the surface topology change of crystalline MnZnFe spinels at $1000 \mathrm{~K}$ under a $\mathrm{N}_{2}$ atmosphere [15]. By conducting similar experiments on $\mathrm{Ni}, \mathrm{Co}$, and $\mathrm{Mn}$, the pressure and temperature at the impact fields can be determined more precisely. This will aid in understanding the mechanism of the MeChem reaction and improving the transformation yield.

For specimens $2 \mathrm{a}$ and $2 \mathrm{~b}$, mild conditions (short milling times up to $1 \mathrm{~h}$ and a low centrifugal acceleration of $20 \mathrm{G}$ ) were used to confirm ammonia formation from Fe nitrate. The change in $\mathrm{pH}$ from 2 to 8 after milling in half an hour showed almost half of the nitrate was transformed to ammonia, most likely in the form of ammonium nitrate. A slight sewage-like odor was detected, but there was no ammonia smell. However, with an increase in milling time, the $\mathrm{pH}$ increased to 9 and the characteristic 
ammonia smell was increasingly observed (specimen 2b). This result indicated that even shorter milling times and lower centrifugal accelerations were sufficient for ammonia formation.

Based on the formation of $\mathrm{Fe}_{3} \mathrm{O}_{4}$ and evolution of $\mathrm{NH}_{3}$ and $\mathrm{NO}_{2}$ (as discussed later), the decomposition reactions of nitrate are assumed to be as follows:

$$
\begin{gathered}
\mathrm{Fe}\left(\mathrm{NO}_{3}\right)_{3} \rightarrow 1 / 3 \mathrm{Fe}_{3} \mathrm{O}_{4}+3 \mathrm{NO}_{2}+5 / 6 \mathrm{O}_{2} \\
\mathrm{Fe}\left(\mathrm{NO}_{3}\right)_{3}+9 / 2 \mathrm{H}_{2} \mathrm{O} \rightarrow 1 / 3 \mathrm{Fe}_{3} \mathrm{O}_{4}+3 \mathrm{NH}_{3}+73 / 12 \mathrm{O}_{2}
\end{gathered}
$$

When these reactions are combined in a one-to-one ratio, the reaction becomes:

$\mathrm{Fe}\left(\mathrm{NO}_{3}\right)_{3}+3 \mathrm{H}_{2} \mathrm{O} \rightarrow 1 / 3 \mathrm{Fe}_{3} \mathrm{O}_{4}+3 / 2\left(\mathrm{NH}_{4}\right) \mathrm{NO}_{3}+37 / 12 \mathrm{O}_{2}$

It is also expected that the well-known selective catalytic reduction of $\mathrm{NO}_{x}$ by $\mathrm{NH}_{3}$ may take place at the same time, producing nitrogen. A typical reaction is expressed as follows:

$$
2 \mathrm{NH}_{3}+\mathrm{NO}_{2}+1 / 2 \mathrm{O}_{2} \rightarrow 3 / 2 \mathrm{~N}_{2}+3 \mathrm{H}_{2} \mathrm{O}
$$

A part of the oxygen is consumed by reaction with the eroded metal. Iron nitrate is stable in the hydrothermal condition, and the decomposition in water is not possible thermodynamically. The decomposition is assumed to take place by forming iron oxide through a donated oxygen from water or nitrate in non-equilibrium conditions under the MeChem field and segregation of the oxide in quenching. Segregated hydrogen and $\mathrm{NO}_{x}$ may form ammonia and others during quenching. However, if $\mathrm{Fe}(\mathrm{II})$ is present, the reduction of nitrite to ammonia by $\mathrm{Fe}(\mathrm{II})$ is observed when the $\mathrm{pH}$ is higher than 7.3 [16]. The reduction of nitrate is also implied under comparable conditions [16]. In the case of Fe nitrate, no reaction was expected to occur as the initial $\mathrm{pH}$ was about 2 (Table 2), even though the eroded metal, Fe, was present at the beginning of milling. This implies that as the MeChem reaction progresses, the increasing $\mathrm{pH}$ leads to an acceleration in the reduction reaction.
More complex combinations of starting materials, including carbides and carbonates, were carried out in specimens 3-5. The results of the IC and GCMS analyses of the products are shown in Figures 3 and 4, respectively, and summarized in Table 3. The total amounts of nitrogen initially charged in each specimen were in

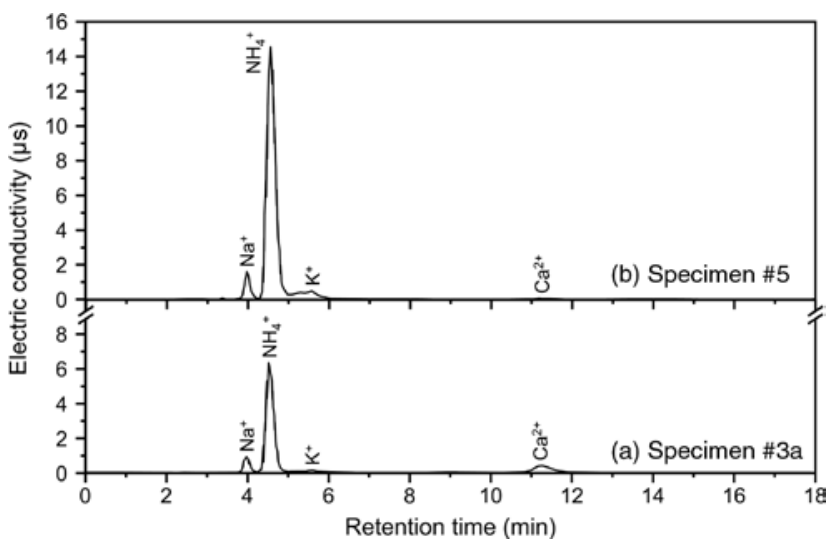

Figure 3: IC spectra of specimens $3 a$ and 5 .

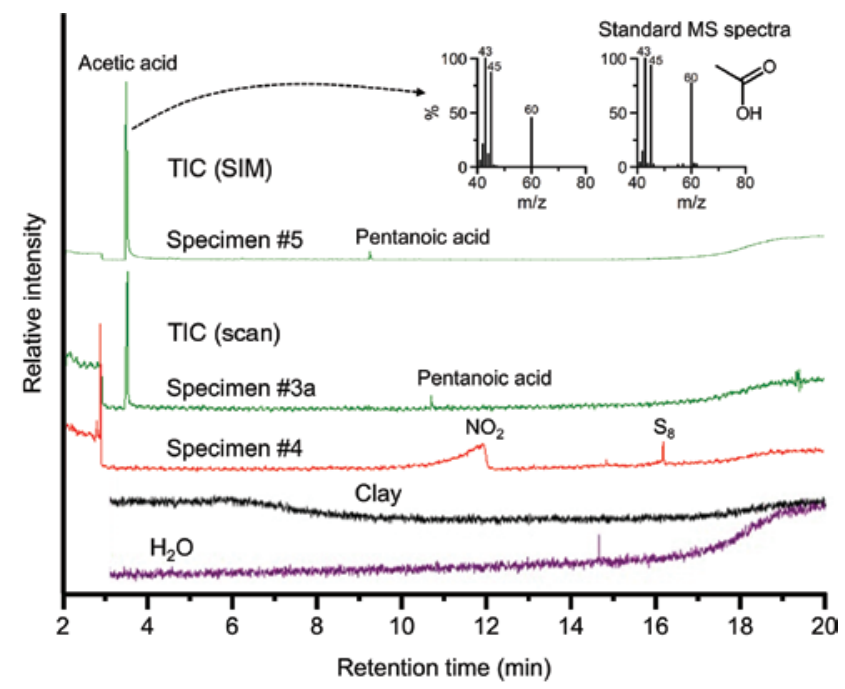

Figure 4: GCMS spectra of specimens 3a, 4, and 5. The spectra of clay and $\mathrm{H}_{2} \mathrm{O}$ are also shown. The insets show MS spectra of the

\begin{tabular}{|c|c|c|c|c|c|c|}
\hline No. & Starting materials & Total N (mg/l) & $\mathrm{NH}_{3}$ content (ppm) & Total C (mg/l) & Acetic acid (ppm) & Initial content $\mathrm{N} / \mathrm{C}(\mathrm{mg} / \mathrm{l})$ \\
\hline $3 a$ & $\mathrm{Fe}_{4} \mathrm{~N}, \mathrm{Fe}_{3} \mathrm{C}$, clay & 910 & 600 & 330 & 50 & $4180 / 7160$ \\
\hline $3 b$ & Fe nitrate, $\mathrm{MnCO}_{3}$, clay & 990 & - & 90 & - & $1390 / 7130$ \\
\hline 4 & Fe nitrate, $\mathrm{CaCO}_{3}$, $\mathrm{FeS}$ & 2090 & 800 & 30 & 0 & $2440 / 21,000$ \\
\hline 5 & Fe nitrate, $\mathrm{Fe}_{4} \mathrm{~N}, \mathrm{Fe}_{3} \mathrm{C}$, clay & 1250 & 1500 & 280 & 100 & $2670 / 6840$ \\
\hline
\end{tabular}
peak observed at about $3.5 \mathrm{~min}$, as well as an acetic acid standard.

Table 3: Analytical results of the TOC, IC, and GCMS measurements.

Total $\mathrm{C} / \mathrm{N}$ content determined by TOC, $\mathrm{NH}_{3}$ content by IC, and acetic acid content by GCMS. 
the range $1390-4180 \mathrm{mg} / \mathrm{l}$. After milling, the conversion yields of nitrogen to ammonia in specimens 3a, 4, and 5 were about $15 \%, 30 \%$, and $50 \%$, respectively. These conversion ratios were much higher than those reported from a previous work [1]. In specimen $4, \mathrm{NO}_{2}$ and $\mathrm{S}_{8}$ were detected (Figure 4). The total $\mathrm{N}$ content measured by TOC $(2088 \mathrm{mg} / \mathrm{l})$ was much larger than the $\mathrm{NH}_{3}$ content (800 ppm). The low $\mathrm{NH}_{3}$ content was likely due to the formation of $\mathrm{NO}_{2}$, although further studies are needed to confirm this.

The TOC results (Table 3) indicate some organic formation, while the MS spectra obtained by GCMS (Figure 4) clearly show the presence of a small amount of acetic acid. From the results of the $\mathrm{Fe}_{3} \mathrm{O}_{4}$ formation (Figure 2), the hydrolysis of $\mathrm{Fe}_{3} \mathrm{C}$, similar to $\mathrm{Fe}_{4} \mathrm{~N}$ hydrolysis, can be assumed to be as follows:

$$
\begin{gathered}
\mathrm{Fe}_{3} \mathrm{C}+4 \mathrm{H}_{2} \mathrm{O} \rightarrow \mathrm{Fe}_{3} \mathrm{O}_{4}+\mathrm{CH}_{4}+2 \mathrm{H}_{2} \\
\mathrm{Fe}_{3} \mathrm{C}+4 \mathrm{H}_{2} \mathrm{O} \rightarrow \mathrm{Fe}_{3} \mathrm{O}_{4}+\mathrm{C}+4 \mathrm{H}_{2}
\end{gathered}
$$

The formation reaction of acetic acid is expected to be as follows:

$$
2 \mathrm{Fe}_{3} \mathrm{C}+10 \mathrm{H}_{2} \mathrm{O} \rightarrow 2 \mathrm{Fe}_{3} \mathrm{O}_{4}+\mathrm{CH}_{3} \mathrm{COOH}+8 \mathrm{H}_{2}
$$

The organic carbon yields observed by the TOC analyses were slightly above $4 \%$ at most, much less than the ammonia yields of $15 \%-50 \%$. These poor yields were due to the loss of the main organic product $\mathrm{CH}_{4}$ from the pots upon opening (whereas $\mathrm{NH}_{3}$ was contained in the aqueous specimen) and the increase in hydrogen gas pressure that inhibited the reaction. The noteworthy TOC values of 90 and $30 \mathrm{mg} / \mathrm{l}$ (specimens $3 \mathrm{~b}$ and 4, respectively) suggested the transformation of stable carbonates such as $\mathrm{MnCO}_{3}$ and $\mathrm{CaCO}_{3}$ to organic molecules, most likely $\mathrm{CH}_{4}$. The measured TOC values were comparable to the solubility limit in water of $35 \mathrm{ppm}$ at room temperature, thus ruling out the formation of other organic molecules.

As shown in Figure 4, acetic acid and a small amount of pentanoic acid were detected in specimens $3 a$ and 5 . Small organic molecules other than acetic acid (70\%-85\% against the detected TOC values) were present, such as methyl alcohol and formaldehyde. Although the conversion yields of acetic acid from the carbon amounts initially loaded were only about $1.5 \%$, the yields were much greater than those reported by Furukawa et al. [5]. According to the above reactions, the yield of acetic acid can be improved by the removal of excess hydrogen. The excess hydrogen tends to bond with a terminal carbon, which is undesirable for producing more complex molecules.
As indicated in Eqs. 4-6, a combination with $\mathrm{Fe}\left(\mathrm{NO}_{3}\right)_{3}$ is preferable as it produces excess oxygen, leading to hydrogen consumption. Therefore, the high conversion yield of specimen 5 compared to that of specimen 3 was due to the addition of $\mathrm{Fe}\left(\mathrm{NO}_{3}\right)_{3}$.

The preliminary measurements by an amino acid analyzer revealed that amino acids such as glycine and alanine might be produced in specimen 5 , whereas no organic materials were present in the starting materials (Figure 5). However, the amount of amino acids detected (0.5-1.5 ppm) was too small to eliminate biological contamination and thus confirm their formation during milling. Conversely, the amount of ammonia detected was over $1000 \mathrm{ppm}$, corresponding to the value given by IC analysis (1400 ppm), with only a small amount of ammonia (10 ppm) detected in the starting materials. This result strongly suggests the formation of ammonia from the nitride and nitrate by the MeChem reaction.

The results from the TOC, GCMS, IC, and amino acid analyses confirmed the formation of ammonia and acetic acid from inorganic starting materials such as nitrides, carbides, carbonates, and water by the micro-impacts of $\mathrm{ZrO}_{2}$ balls during the MeChem reaction. Since rocks and sand can act as $\mathrm{ZrO}_{2}$ balls, these results lead to the following assumption. On the early Earth some billions of years ago, extraterrestrial impacts by meteorites generated gigantic tremors and internal friction in terrestrial crusts that resulted in micro-impacts between rocks and sand, triggering the formation of organic precursors from the inorganic materials in the crusts. This formation route should be considered alongside the route to precursors in the hot plumes produced by meteorites $[1,5]$. Since the temperature and pressure increase further in a deep terrestrial crust, even small tremors spread over long

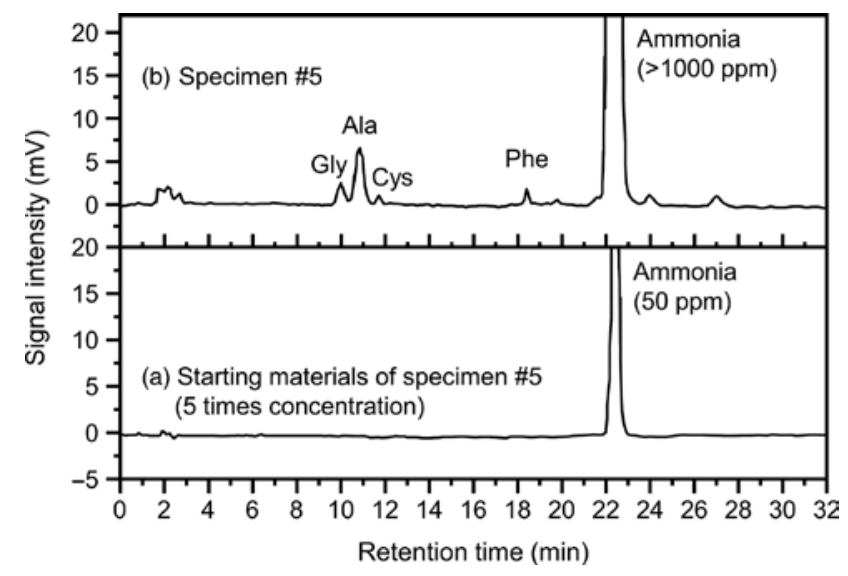

Figure 5: Analysis of amino acids in specimen 5 and its starting materials. 
distances would effectively promote the formation of precursors. The MeChem reaction in the crusts thus offers a new route for precursor formation.

The results obtained for mild milling at $20 \mathrm{G}$ for $0.5 \mathrm{~h}$ (specimen 2a) suggested that even a weak impact or short milling time is sufficient to produce ammonia. Such impacts are commonly observed around the world today. For instance, huge earthquakes cause tremors or impacts near $1 \mathrm{G}$, and the tremors may reach well over $20 \mathrm{G}$ in the vicinity of the hypocenters. These tremors are expected to produce precursors through MeChem reactions in crusts or subducted ocean floors rich in nitrate and carbonate sediments [17]. As mentioned above, since the temperature and pressure are high in deep crusts, even slight tremors are effective. The presence of an effective catalyst can boost the production of precursors even further. Such arguments lead to the hypothesis that precursors were formed by crust events such as earthquakes and tidal movements, and accumulate in huge reaction volumes over the years and greatly surpass the amounts of precursors produced by much rarer meteorite impacts. This hypothesis may also give a basis for the abiotic petroleum formation theory.

\section{Conclusions}

Micro-impacts achieved by a high-energy ball mill enabled the formation of ammonia and acetic acid from iron nitride, nitrate, carbide, and water in high yields. Although the MeChem reaction due to each micro-impact between the balls results in only a tiny amount of products, frequent collisions between numerous balls during milling led to a satisfactory yield. The observed experimental results were as follows:

- Nitrogen contained in the starting iron nitride was converted to ammonia with a yield of over $30 \%$ in the MeChem reaction with water at $150 \mathrm{G}$ for $64 \mathrm{~h}$.

- The decomposition of iron nitrate to iron oxide was observed at $20 \mathrm{G}$ in half an hour, even though this reaction is not possible thermodynamically. This decomposition reaction can offer a metallic acid waste processing by the simple mechanical process without any alkaline sources.

- The organic carbon yields from iron carbide and nitrate were estimated to be $4 \%$ by TOC analysis and acetic acid yields to be 100 ppm by GCMS measurements after the MeChem reaction for over $30 \mathrm{~h}$ at 40 G. A small amount of pentanoic acid was also detected.
This study demonstrated that not only a grinding of particles but also a reaction with solvents, a formation of stable oxides, and even a formation of organic materials can occur in a milling process. The MeChem reaction with micro-impacts is proposed as a new route to precursors: extraterrestrial impacts generate gigantic tremors, resulting in micro-impacts between the rocks and sand in terrestrial crusts. Large amounts of precursors are thus formed in the crusts, which act as MeChem cradles. Considering the complex mechanism of the MeChem reaction, many kinds of precursors including amino acids may be produced through various combinations of inorganic reactants and processing conditions. Therefore, the MeChem reaction utilizing a high-energy ball mill will present the formation and evolution of inorganic and organic materials on early Earth.

Acknowledgements: The authors wish to thank Mr. K. Itakura (Kurimoto) and Mr. Y. Ochiai (Sankei HighPrecision) for the cooperation in the High $G$ milling experiments, Mr. T. Kameda (ITES) for his elaborated work with the GCMS and IC measurements, and Mr. H. Suzuki (Hitachi High-Tech Science Corporation) for the amino acid analysis.

Conflict of interest statement: The authors declare to have no conflicts of interest regarding this article.

\section{References}

[1] Nakazawa H, Sekine T, Kakegawa T, Nakazawa S. Earth Planet. Sci. Lett. 2005, 235, 356-360.

[2] Brandes JA, Boctor NZ, Cody GD, Cooper BA, Hazen RM, Yoder Jr HS. Nature 1998, 395, 365-367.

[3] Kasting JF, Howard MT. Phil. Trans. R. Soc. Lond. B 2006, 361, 1733-1742.

[4] Sekine T. Eur. J. Solid State Inorg. Chem. 1997, 34, 823-833.

[5] Furukawa Y, Sekine T, Oba M, Kakegawa T, Nakazawa H. Nat. Geosci. 2009, 2, 62-66.

[6] Dachille F, Roy R. Nature 1960, 186, 34, 71.

[7] Nogi K, Naito M, Kondo A, Nakahira A, Niihara K, Yokoyama T. Funtai oyobi Funmatsu Yakin 1996, 43, 396-401.

[8] Kugimiya, K. In Ceramic Innovations in the 20th Century, Wachtman Jr, JB, Ed., American Ceramic Society: Westerville, 1999, p. 131.

[9] Šepelák V, Düvel A, Wilkening M, Becker KD, Heitjans P. Chem. Soc. Rev. 2013, 42, 7507-7520.

[10] Uno M, Nishimoto S, Kameshima Y, Miyake M. Int. J. Hydrogen. Energy 2013, 38, 15049-15054.

[11] Chen Y, Calka A, Williams JS, Ninham BW. Mater. Sci. Eng. A 1994, 187, 51-55. 
[12] Hashishin T, Tan Z, Yamamoto K, Qiu N, Kim J, Numako C, Naka T, Valmalette JC, Ohara S. Sci. Rep. 2014, 4, 4700.

[13] Blank JM. US patent No. 3027327, 1962.

[14] Reed, TB. In Ferrites: Proceeding of the International Conference, Hoshino, Y, lida, S, Sugimoto, M, Eds., University of Tokyo Press: Tokyo, 1970, 289-295.
[15] Hirota E, Kugimiya K. Nat. Tech. Rep. 1976, 6, 753-773.

[16] Summers DP, Chang S. Nature 1993, 365, 630-633.

[17] Hatakeyama K, Katayama I, Hirauchi K, Michibayashi K. Sci. Rep. 2017, 7, 13870. 